\title{
Welcome to the Maker Movement: Parallel Education Pathways of Adult Makers
}

\section{Ms. Chrissy Hobson Foster, Arizona State University}

Chrissy Foster is a Ph.D. candidate in Engineering Education at the Mary Lou Fulton Teachers College of Arizona State University. Her dissertation study explores the approaches to technical innovation within Native American communities.

\section{Mr. Aubrey Wigner, Arizona State University}

Aubrey Wigner is a PhD student in Human and Social Dimensions of Science and Technology at Arizona State University. He has an undergraduate degree in Chemical and Biochemical Engineering and a Masters in International Political Economy of Resources, both from the Colorado School of Mines. His research focuses on integrating Makerspaces and Hackerspaces with higher education to enhance learning through hands on interdisciplinary practices. He is also interested in how organizations and individuals engage in technological innovation.

\section{Dr. Micah Lande, Arizona State University, Polytechnic campus}

Micah Lande, Ph.D. is an Assistant Professor at the Polytechnic School in the Ira A. Fulton Schools of Engineering at Arizona State University. He teaches human-centered engineering design and innovation courses in the engineering and manufacturing engineering programs. Dr. Lande researches how technical and non-technical people learn and apply a design process to their work. He is interested in the intersection of designerly epistemic identities and vocational pathways. Dr. Lande received his B.S in Engineering (Product Design), M.A. in Education (Learning, Design and Technology) and Ph.D. in Mechanical Engineering (Design Thinking) from Stanford University. Dr. Lande is the PI on the NSF-funded project "Should Makers Be the Engineers of the Future" and a co-PI on the NSF-funded project "Might Young Makers Be the Engineers of the Future?"

\section{Dr. Shawn S Jordan, Arizona State University, Polytechnic campus}

SHAWN JORDAN, Ph.D. is an Assistant Professor of engineering in the Ira A. Fulton Schools of Engineering at Arizona State University. He teaches context-centered electrical engineering and embedded systems design courses, and studies the use of context in both K-12 and undergraduate engineering design education. He received his Ph.D. in Engineering Education (2010) and M.S./B.S. in Electrical and Computer Engineering from Purdue University. Dr. Jordan is PI on several NSF-funded projects related to design, including an NSF Early CAREER Award entitled "CAREER: Engineering Design Across Navajo Culture, Community, and Society" and "Might Young Makers be the Engineers of the Future?" He has also been part of the teaching team for NSF's Innovation Corps for Learning, and was named one of ASEE PRISM's "20 Faculty Under 40" in 2014.

Dr. Jordan also founded and led teams to two collegiate National Rube Goldberg Machine Contest championships, and has co-developed the STEAM Labs ${ }^{\mathrm{TM}}$ program to engage middle and high school students in learning science, technology, engineering, arts, and math concepts through designing and building chain reaction machines. He has appeared on many TV shows (including Modern Marvels on The History Channel and Jimmy Kimmel Live on $\mathrm{ABC}$ ) and a movie with his Rube Goldberg machines, and worked as a behind-the scenes engineer for season 3 of the PBS engineering design reality TV show, Design Squad. He also held the Guinness World Record for the largest number of steps - 125 - in a working Rube Goldberg machine. 


\section{Introduction}

\section{How to Understand Engineering Life Pathways}

Engineering is increasingly understood as a lifelong learning pathway rather than an event that happens only in a university setting. The National Academy of Engineering's the Engineer of 2020 identifies lifelong learning, practical ingenuity, analytic skills, business management, creativity, cognitive flexibility, ethics, leadership, professionalism, and communication as the knowledge and skills that will be valuable for engineers in the future. These skills can be learned both within, and outside of, traditional engineering education. In order to understand how engineering education manifests during the course of a life, or how engineering skills and mindsets are acquired later in life, it is vital to understand how skills, knowledge, and tacit knowledge are built. This paper explores one method for discovering how engineers are made, both through traditional and non-traditional processes. We explored the life pathways of Makers, an interdisciplinary collective of engineers, scientists, hobbyists, and artists who are focused on the creation of physical artifacts that usually incorporate technology. This group embraces many of the traits highlighted in the Engineer of 2020, with specific focus on lifelong learning, practical ingenuity, creativity, and cognitive flexibility. To do so, we used a combination of qualitative techniques for data collection including a screening questionnaire, artifact elicitation interviews, and critical incident interviews. This paper, part of a larger work in progress by the authors, will expand on the collection methods used in order to inform others of possible approaches for understanding the skills learned and pathways taken by a sector of the adult community who embody many of the qualities vital to the engineer of 2020. In addition, by exploring the life pathways of makers, we can begin to see how classically trained engineers renew their passion for engineering and how adult non-engineers learn and engage with engineering skills and knowledge. By presenting a method for assessing the skills learned by Makers along with descriptive examples of adults engaged in engineer-esque activities, we hope to further the conversation surrounding educating the engineer of the future.

\section{Broadening Engineering Pathways}

A more inclusive vision of engineering crossed with making could build future engineering capacity as well as raise awareness to the general public of the work and impact such work offers. Findings from the Center on the Advancement of Engineering Education's Academic Pathways Study studying undergraduate persistence in engineering and students' pathways by and through engineering studies, found two groups of students with different motivations for engagement. ${ }^{1}$ The first seeks financial security, overcoming barriers of foundational math and science courses to continue, aiming for graduation. The second approached their studies with an intrinsic psychological motivation, seeking meaning and impact through their studies. Findings from a study on nontraditional students in engineering identified that the rate of graduation is dismal for nontraditional students who switch into engineering and that there may be additional barriers for nontraditional students. ${ }^{2}$ Although all Makers do not wholly fit the profile for nontraditional students (e.g., delaying enrollment in higher education and attending part-time for at least part of the academic year), many do. Examining Makers' pathways will contribute to understanding how we might increase access to engineering and improve diversity of the engineering student population. Engineering is notable for low migration to the major. Findings 
from a study on the persistence, engagement, and migration to engineering identified that engineering students were similar to students of other majors in relation to persistence and engagement, suggesting that engagement is established prior to persistence. ${ }^{3}$ Identifying qualified engaged students who may enter engineering presents an avenue for increasing access to engineering.

Our ambition is to change the conversation to highlight the efficacy and possibilities for those who are engaged in making and seeking meaning and impact through their studies. The stories and life pathways of adult learners engaged in Making can offer valuable insight into how we might identify practices that promote the access and success of a larger and more diverse population of students. We do not equate engineering students, practicing engineers, and Makers completely but find the possible overlaps and stories of pathways within to be possible for transformational change in our field. Makers are engaged in activities that embody the Engineer of 2020 (e.g., lifelong learning, creativity, and practical ingenuity). By studying Makers, we can consider the multiplicity of pathways into engineering majors and careers.

\section{What is a Maker?}

The Maker Movement is a developing sub-culture that values the tinkering, hacking, re-making, and creating of technical artifacts, often done without prior expertise. ${ }^{4-6}$ Making comes from an imaginative, creative mind-space, done outside the confines of established engineering education curricular activities. ${ }^{4-6}$ Making has a do-it-yourself ethos and is historically rooted in efforts like Popular Mechanics magazine who demystified everyday stuff for hobbyists and the Whole Earth Catalog: Access to Tools ${ }^{7}$ who surveyed everyday tools for the counterculture movement of the 1960s. Additional real-world touchstones are the growth of Radio Shack stores and the 1980s television program MacGyver where the lead character would resolve each episode's predicament by fashioning an escape plan out of found objects. ${ }^{8}$ Technology and sharing of information via the Internet has greatly increased the ability for smaller communities with shared interests to coalesce and grow.

The label "Maker" is a self-determined one assigned by affinity or involvement in a larger Making community. Makers are do-it-yourself-minded individuals participating in informal communities (doing-it-with-others) that support and celebrate building and prototyping technical proof-of-concept exploration and ad-hoc product development. A Maker is a modern-day tinkerer and hands-on doer and fashioner of stuff. The range of expertise could be large but novices and experts alike share an enthusiasm and appreciation for building and creation. Individuals and groups embark on projects of all sorts, led primarily by their interests and curiosities, informed by their skills or the skills they want to learn. They make creative efforts like fire-breathing robots as performance art, combining contributions from community members with electrical, mechanical and embedded systems know-how ${ }^{9}$ or construct intricate, wooden geometric puzzles CNC'd from exotic woods commissioned by patrons. ${ }^{10}$ They show off their work readily and share their technical recipes with those interested.

Makers participate in communities of practice. ${ }^{11}$ They populate maker spaces and hacker spaces ${ }^{8}$ and use commercial ventures like Tech Shop ${ }^{12}$ to gather with other Makers. A significant part of such participation is to benefit from opportunities to continue learn from, teach and mentor other 
Makers. Much like professional engineering, making does not often take place as a solo activity and instead is part of a problem solving and creation community.

Make magazine and the Maker Faire are champions of the Make movement and described as "a central organ of the maker movement". ${ }^{13}$ Founded in 2006 as a quarterly publication, Make magazine presents "DIY Projects, Inspiration, How-tos, Hacks, Mods \& More". ${ }^{16}$ Its pages celebrate the people engaged in making and is a modern-day equivalent of the Whole Earth Catalog crossing technology with the category of tools covered. Craft and Ambidextrous Journal of Design have been additional efforts to capture the people and processes of crafting and design thinking respectively. Maker Faire has been an outreach effort of Make magazine, convening flagship, multi-day fair events in select cities and supporting smaller, regional one-day events around the country. Its credo is to "celebrate arts, crafts, engineering, science projects and the DIY mindset." "The first Maker Faire was in the San Francisco Bay Area in 2006, attracting 100 exhibitors and 40,000 attendees. In 2010, the Bay Area Maker Faire hosted 1,000 makers and had 80,000 in attendance. ${ }^{15}$ Maker Faires have been held there since then, with Austin added for 2007 and 2008, and Detroit and New York in 2010 and 2011. Makers volunteer to exhibit at Maker Faire festivals. There are also workshops and talks on a main stage as well as special events scheduled throughout the event. It is a place where Makers come and share what they have made and learned.

In addition to studying the educational pathways of Makers, we also have additional ongoing work to explore what Making is, and what the Maker Community is. We allow Makers to selfidentify through their participation in and attendance at Maker Faire events, and ask for them to define Making and Engineering. The similarities (and differences) between these areas are discussed by the authors in another paper. ${ }^{6}$

\section{Research Design}

This paper presents an on-going study to explore the educational pathways of adult Makers and how they intersect with engineering. This research is guided by the following research questions and research design.

$R Q 1$. What can engineering educators learn from adult Makers education pathways to inform education for future engineers?

$R Q 2$. What can we learn about the pathways of Makers through the qualitative research approach, constructivist grounded theory, utilizing artifact elicitation interview and critical incident interview methods?

This research, guided by $R Q 1$ and $R Q 2$, is situated within a broader four-year study explores making as a means of engaging both current engineering students as well as adults and precollege students in the engineering landscape described in The Engineer of 2020, ABET $a-k$, and 21st Century Skills.

The study was designed with Crotty's ${ }^{17}$ four elements of a research study (epistemology, theoretical perspective, methodology, and methods). The elements of Crotty are particularly salient for our research design because they inform each other; epistemology informs theoretical 
perspective, which informs methodology, which informs the selection of methods. Table 1 describes the four elements, specific theories and methods selected for this study and the rationale.

Table 1: Elements of a Research Study by Crotty ${ }^{17}$

\begin{tabular}{|l|l|l|l|}
\hline & Definition & Selected & Rationale \\
\hline Epistemology & $\begin{array}{l}\text { Theory of } \\
\text { knowledge }\end{array}$ & $\begin{array}{l}\text { Constructivism } \\
\text { Knowledge is constructed } \\
\text { through human-world } \\
\text { interaction }\end{array}$ & $\begin{array}{l}\text { To understand how and what Makers } \\
\text { learn through their creations }\end{array}$ \\
\hline $\begin{array}{l}\text { Theoretical } \\
\text { Perspective }\end{array}$ & $\begin{array}{l}\text { Philosophy that } \\
\text { informs } \\
\text { methodology }\end{array}$ & $\begin{array}{l}\text { Constructionism } \\
\text { Meaning is created through } \\
\text { constructing \& sharing } \\
\text { artifacts }\end{array}$ & $\begin{array}{l}\text { To understand how Makers create } \\
\text { meaning through the design and } \\
\text { sharing of their creations }\end{array}$ \\
\hline Methodology & $\begin{array}{l}\text { Design } \\
\text { connecting } \\
\text { methods to } \\
\text { outcomes }\end{array}$ & $\begin{array}{l}\text { Constructivist Grounded } \\
\text { Theory } \\
\text { Researcher is the author of } \\
\text { participant's voice and } \\
\text { meaning }\end{array}$ & $\begin{array}{l}\text { Little is known } \\
\text { know and their pathways. Methods } \\
\text { must be sensitive to study objectives: } \\
\text { to understand what Makers learn and } \\
\text { how their pathways intersect } \\
\text { w/engineering. }\end{array}$ \\
\hline Methods & $\begin{array}{l}\text { Implementation } \\
\text { of methodology }\end{array}$ & $\begin{array}{l}\text { Screening questionnaire } \\
\text { Artifact elicitation } \\
\text { interviews } \\
\text { Critical incident technique } \\
\text { interviews }\end{array}$ & $\begin{array}{l}\text { To screen potential participants } \\
\text { To understand Makers' creations / } \\
\text { knowledge / skills learned by } \\
\text { creating } \\
\text { To study Makers' attitudes about and } \\
\text { pathways intersecting with } \\
\text { engineering }\end{array}$ \\
\hline
\end{tabular}

\section{Research Methods}

The study began with administering a participant screening questionnaire to potential participants, followed by an initial stratified purposeful sampling of participants who meet criteria self-identifying as Makers and being adults (18 or older). Artifact elicitation interviews, based on the method of photo elicitation, ${ }^{21}$ of approximately 15 minutes each were conducted with each participant on site at Maker Faires in New York and the Bay Area. A longer, one hour, critical incident technique interview ${ }^{22}$ was conducted with each participant in the months following each Maker Faire.

Throughout the study, part of the research team conducted inductive analysis on the transcribed interviews, which provided feedback to inform questions asked in the interview protocol. Another part of the research team is actively conducting the deductive analysis (fitting data to existing theory) based on relevant theories, including pathways theory and Bloom's Revised Taxonomy ${ }^{23}$. Each part of the research team was designated a coding approach so as to reduce bias in the identification of themes. 
As part of the larger work in progress, the results from the inductive and deductive analyses are actively being triangulated to generate a preliminary theory of Maker knowledge, skills, attitudes, and pathways. New theories discovered from the inductive analysis but absent in the deductive analysis informed the theoretical sampling cycle to choose additional participants to explore the new themes in more depth (see Figure 1). One such example is the parallel pathways of Makers (Makers from different backgrounds who make similar artifacts) that came to light during inductive analysis; this is the focus of the study presented in this paper. The larger work will present a theory and profiles of individual Makers. As part of this, the triangulated theory will describe the knowledge, skills, and attitudes of Makers, along with how their pathways intersect with formal engineering education.

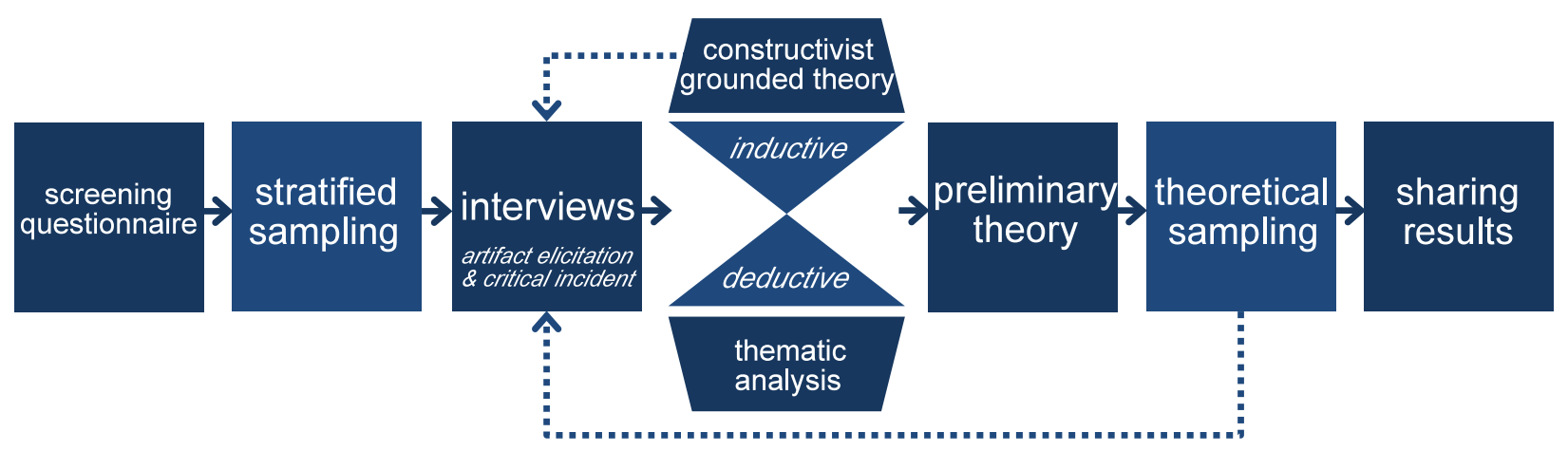

Figure 1: Research process (adapted from Martin ${ }^{24}$ which also uses constructivist grounded theory to study the educational experiences of engineering students)

\section{Population and Sampling}

This study relied upon a population of adult Makers in order to understand how their pathways intersect with formal engineering education. We sought out Makers who participate in Maker Faires around the country, in addition to Makers who publish articles in MAKE magazine. 42 exhibitors at two flagship Maker Faires were recruited for this study (see Table 2).

Table 2: Participant recruitment and interviews (participant pool, location, date)

\begin{tabular}{|c|c|c|c|c|}
\hline & Round 1 & Round 2 & Round 3 & Round 4 \\
\hline Makers & 7 & 9 & 12 & 14 \\
\hline $\begin{array}{c}\text { Location, } \\
\text { Date }\end{array}$ & New York & Bay Area & New York & Bay Area \\
September 2012 & May 2013 & September 2013 & May 2014 \\
\hline
\end{tabular}

The Bay Area Maker Faire draws over 500 exhibitors. In order to select participants to answer the research questions about Makers, a stratified purposeful sampling strategy ${ }^{17}$ was used for initial selection of the participants. Participants were selected to maximize variation across the strata described in Table 3, while oversampling for underrepresented groups and ensuring that all participants self-identify as Makers. This sampling strategy was appropriate to target the Maker population relevant to the research questions, whereas representative sampling may not 
provide a complete picture of knowledge, skills, attitudes, and pathways of Makers necessary to inform theory generation. Each participant received a monetary incentive for their time.

Table 3: Stratifications for purposeful sampling

\begin{tabular}{|l|l|}
\hline Primary Strata & Secondary Strata \\
\hline - $\begin{array}{l}\text { Self-identified Maker } \\
\text { - With/without formal engineering education } \\
\text { experience (e.g., engineering degree) }\end{array}$ & - With/without an engineering-related career \\
With/without informal engineering education \\
$\begin{array}{l}\text { experience (e.g., robotics team, hacker space) } \\
\text { Member of an underrepresented group based on } \\
\text { ethnicity and gender }\end{array}$
\end{tabular}

Makers who have a formal engineering degree were selected to provide insight into how formal engineering education has helped them in their chosen pathway. Makers who have informal engineering education experience (e.g., robotics team) were selected to provide breadth to the study and illuminate how informal education experiences influence engineering pathways and career choices. Non-engineers were included to see how those without engineering background were engaged with the high-tech aspects of making and to understand to what degree they were learning and incorporating engineering in their work.

After each round of data collection, theoretical sampling done "on the basis of the emerging concepts, with the aim being to explore the dimensional range or varied conditions along which the properties of concepts vary". ${ }^{20}$ Theoretical sampling is intended to strengthen the theory through purposeful selection of participants who address weaknesses in the emergent theory, which is a key feedback element to a strong parallel inductive-deductive research design. Additional participants were sampled until theoretical saturation in the model was reached.

At the conclusion of the study, 42 adult Makers had participated with the artifact elicitation interview, and 25 of those participants went on to complete the critical incident interview. We seek to identify factors and see this as a first step to explore our research questions; we do not claim to generalize or predict, so a smaller $\mathrm{N}$ is appropriate for our study aims. With our qualitative research approach, the exploratory nature of our research questions and theorybuilding efforts, we do expect that our number of interviews will produce more than enough "thick description" 26 for the study's purpose to discern a pattern about participants' knowledge, skills, attitudes and pathways through artifact elicitation and critical incident technique interviews.

\section{Data Collection}

\section{Screening Questionnaire}

Prior to each Maker Faire, all Makers with information publicly available online were contacted through email and asked to complete a short online screening questionnaire. The results were collected in a database. The questionnaire consisted of short answer questions (see Table 4) and 
requested contact information and their exhibit location at the Maker Faire. Results from the questionnaire were used to select initial participants using the stratified purposeful sampling strategy described above, and also used to contextualize the critical incident technique interview questions.

Table 4: Screening Questionnaire Questions

\begin{tabular}{|l|l|}
\hline Are you a Maker? & Primary Strata \\
\hline How many years are you a Maker? & Secondary Strata \\
\hline As a Maker, what do you Make? & Theoretical Sampling \\
\hline Why are you attracted to Making? & Theoretical Sampling \\
\hline Have you been involved with any group Maker activities/? Please describe. & Primary Strata \\
\hline $\begin{array}{l}\text { Have you taken any engineering classes/ have an engineering degree? Please } \\
\text { describe. }\end{array}$ & Primary Strata \\
\hline Do you have an engineering related job/career? Please describe. & Secondary Strata \\
\hline Ethnicity, Gender & Primary Strata \\
\hline Age & Secondary Strata \\
\hline
\end{tabular}

\section{Artifact Elicitation Interviews}

Semi-structured artifact elicitation interviews were conducted in person with 41 Maker participants and via Skype with one Maker participant to examine the knowledge and skills the Maker developed as a result of making artifacts. For the 41 interviews that were conducted in person, we located each participant at their exhibit booth at the Maker Faire where they were typically interacting with Maker Faire attendees and showing/demonstrating their creation. Following obtaining research consent, we spent approximately fifteen minutes with the Maker participant, asking them to describe their artifact, show us how their artifact works, their process for making, and the knowledge, skills, and attitudes they learned from making (see Table 5). We asked probing questions about the artifact to elicit "thick description" each round of data collection based on emergent themes that were discovered during early analysis.

Table 5: Sample Artifact Elicitation Questions

\begin{tabular}{|l|l|}
\hline $\begin{array}{l}\text { Can you tell me about what you brought to the Maker Faire? } \\
\text { (probe) What technology does it use? } \\
\text { (probe) Can you show me how it works? }\end{array}$ & Knowledge and skills \\
\hline $\begin{array}{l}\text { What knowledge and skills did you have to learn to make this [insert name of } \\
\text { artifact]? }\end{array}$ & Knowledge, skills \\
\hline Where did you learn these things? & Lifelong learning \\
\hline $\begin{array}{l}\text { How did you come up with the idea for this [insert name of artifact]? } \\
\text { (probe) What could you improve in your [insert name of artifact]? }\end{array}$ & Attitudes \\
\hline
\end{tabular}

\section{Constructivist Critical Incident Technique Interviews}

Semi-structured constructivist critical incident technique interviews ${ }^{22}$ were conducted via Skype after the Maker Faire with 25 Maker participants (from the same pool of Maker participants who completed the artifact elicitation interview) to examine the educational and career pathways of Makers and how they intersect with formal engineering education and careers in engineering. 
Following each Maker Faire, all participants who completed an artifact elicitation interview asked to participate in the semi-structured constructivist critical incident technique interview via email. All Maker participants who completed this second interview were contacted via Skype and interviewed for approximately one hour. The interview consisted of questions (see examples, Table 6) designed to examine decision points in their educational pathway and how they relate to engineering. Questions evolved after each round of data collection based on emergent themes that were discovered during early analysis. Klein ${ }^{27,28}$ used critical incident technique interviews to study decision making in a variety of fields, and the method have been used very successfully in engineering education research. This technique aligns well with RQ1of this study to understand decision points contributing to pathways intersecting with engineering.

Table 6: Sample Constructivist Critical Incident Technique Interview Questions

\begin{tabular}{|l|l|}
\hline What would you say "making" is for you? & Attitudes \\
\hline Tell me the story of how you became a Maker. & Pathways \\
\hline $\begin{array}{l}\text { How did your educational experience prepare you for the making you are } \\
\text { doing now? } \\
\text { (probe) Have you found any gaps in your knowledge (e.g., things you wish } \\
\text { you would have learned or things you did not learn well enough)? }\end{array}$ & $\begin{array}{l}\text { Lifelong learning/ } \\
\text { Pathways }\end{array}$ \\
\hline $\begin{array}{l}\text { What is your job? } \\
\text { (probe) Why did you/did you not pursue an engineering career? }\end{array}$ & Pathways \\
\hline Where do you see yourself in 5-10 years? & Pathways \\
\hline
\end{tabular}

\section{Data Analysis}

To examine the pathways of the Maker participants, interview transcriptions were analyzed inductively. Open coding ${ }^{20}$, theoretical memoing ${ }^{29}$, and sorting was used to identify key influences in the participants' pathways. Sorting and theoretical coding ${ }^{29}$ are being used to connect the resultant themes into a theory for the larger work in progress. Other members of the research team are actively deductively analyzing the data using thematic analysis ${ }^{30}$ based on a coding scheme derived from relevant conceptual frameworks, including pathways theory. ${ }^{1}$ Once complete, the deductive analysis will be used in a confirmatory and triangulatory capacity for the larger work in progress.

\section{Data Analysis Challenges}

Characterizing Makers and their pathways is a challenging endeavor. Most Makers do not as a rule follow traditional pathways, i.e. education followed by a career in their field; instead, they cross between disciplines, make major career changes, learn diverse skills and knowledge, and so on - often for the purpose of realizing their Making goals. The Making community is built on a culture of acceptance and supporting one another in their individual and group interests and pursuits.

\section{Results}

The findings provide an in-depth perspective through specific pathways of adult Makers, some of whom are nontraditional learners, and present considerations for opportunities for bringing 
qualified individuals to engineering to increase the diversity of the engineering student population.

\section{A View from the Top}

The screening questionnaire data provides a snapshot of the Makers' reported educational backgrounds and careers (see Table 8 and Table 9). Of the 42 participants, 25 have formal engineering education experience, 13 have an engineering degree or are in progress for an engineering degree, and 21 have informal engineering education experience (e.g, robotics clubs). From the same participant pool, 22 reported having an engineering-related career ( 7 reported not having an engineering-related career). Consolidating the responses for educational backgrounds and careers into like categories reveals that the frequency of educational background and career for the art and STEM categories are somewhat proportional. Additionally, most Makers have STEM and/or art education backgrounds and careers, in addition to being involved with entrepreneurship in their career. From this vantage point, it seems as though the Makers' pathways are mostly linear (e.g., an individual who has an educational background in STEM has a career in STEM). Looking across the educational background to career for the individual participants reveals that 34 pathways are linear, with 16 including entrepreneurship in the career. Two pathways show cross over between art and STEM and four show cross over between multiple categories (e.g., tradesman, professional, business). Twenty-four of the 42 interviewees had careers or education experiences bridging across multiple categories. This leads to a graphic representation with more than 42 data points. The interviewees reported a combined 41 different education paths, ranging from trade school to STEM PhDs, and 22 careers from research engineer to retiree.

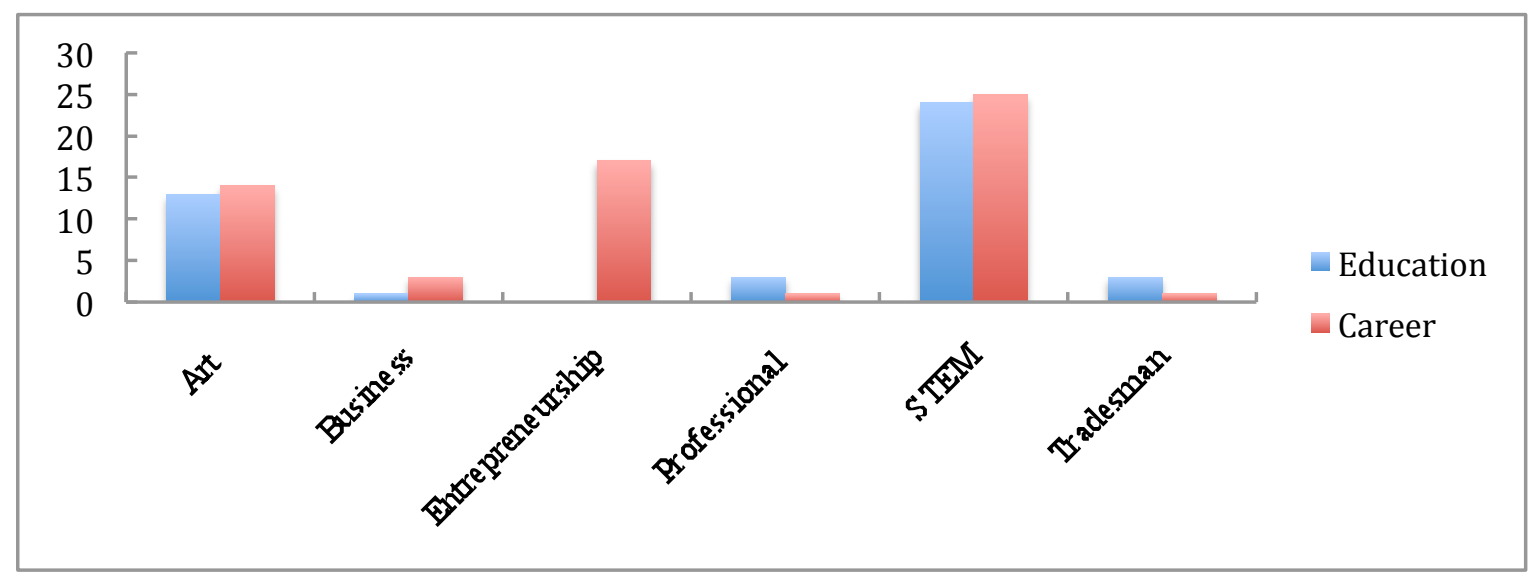

Figure 2. Educational Backgrounds and Careers of the Makers (Consolidated Categories)

\section{A New Direction for Analysis: Parallel Pathways}

Throughout the collection of interviews with Makers and inductive analysis, a theme emerged where Makers from different educational backgrounds and with different careers (e.g., art, STEM, business) were making artifacts that had similar purpose. These groupings of Makers, based upon the artifacts they made, became an interesting technique to study the complexity of Makers' pathways. Furthermore, most of these artifacts embodied engineering skills such as 
computer programming, circuits, prototyping, acoustics, and biomedical interfaces. This process for comparison is intended to prompt new questions, uncover new dimensions, and produce

alternatives. ${ }^{31}$ This is important when studying pathways to consider the multiplicity of ways that Makers arrive at making and how it intersects with engineering. With this new direction, artifacts produced by the Makers were grouped based upon similarity (see Table 10). The focus for analysis within each case was on the events, activities, and processes they were key to the Makers' pathways. While the data from screening questionnaires provides an interesting view at the major milestones along the Makers' life pathways, it tells us little about the specifics events that occurred in their pathway and the skills that they gained through the activities and events. The initial survey of artifact categories included 3D printing, biofeedback devices, building with common materials, costumes, toys, music, paint, sensors, smart watering, and travel. In this broad range of topics, $70 \%$ of the projects studied involved aspects of electrical or computer engineering, $80 \%$ involved some strong STEM component.

\section{Findings: Parallel Pathways}

Examples of parallel pathways are musical artifacts, large-scale artifacts, toys, biofeedback devices, and costumes, to name a few. For this paper, we focus on musical artifacts to demonstrate the multiple, parallel pathways that Makers take to making their artifacts and the contextual events and activities that are critical to the direction of these pathways. This case was selected as an example for this paper because the Makers within musical artifacts have different educational backgrounds and different careers, despite making similar artifacts. Examining the similarities and differences in the case will hopefully illuminate how making intersects with engineering and how engineering pathways might be broadened. We acknowledge there are limitations with this stage of analysis; the findings are contextual, dependent upon thick descriptions, and have not been undergone comparative analysis across the cases. In-depth comparison within the cases and across the cases needs to be performed to better understand the pathways of Makers and how they intersect with engineering. A future expansion of this paper will address multiple pathways based on like artifacts to provide a richer scope of analysis.

\section{Case Study: Musical Artifacts}

Stephen: So I, I build all these instruments and I get enough crazy people together to play with me on a stage with them.

Interviewer: So is that how you decided to build these artifacts is that you were part of a band? How did the idea come about?

Stephen: Uh the band actually grew out of the artifacts. I'm just a person who's really interested in my world and I've always been interested in technology and oddly I got into sound as an art form from sculpture which is my undergraduate degree and I got into sound in the you know in the late nineties when home computers were really getting to the point where you could really do something with sound and it didn't take three days of rendering. And um oddly from there I moved very deep into computer sound and then I regressed to like nineteen seventies circuit building of sound that I put into these cool retro boxes. 
Alejandro, Stephen, and Cane make musical artifacts (see Figure 3). Cane makes musical amplifiers from up-cycled products (e.g., soda cans and lunch boxes) for his growing business. Stephen makes musical instruments from discarded products (e.g., children's toys) for hobbyist, improvisational performances with an organized group. Alejandro makes robots that dance to micro symphonies. Each of these Makers used technical knowledge and skills to bring their artifacts to fruition; however, each of their pathways to technical activities is different. Through three stages of data collection (screening questionnaire, artifact elicitation interview, and critical incident interview), new dimensions of their individual pathways were uncovered (see Figure 4).
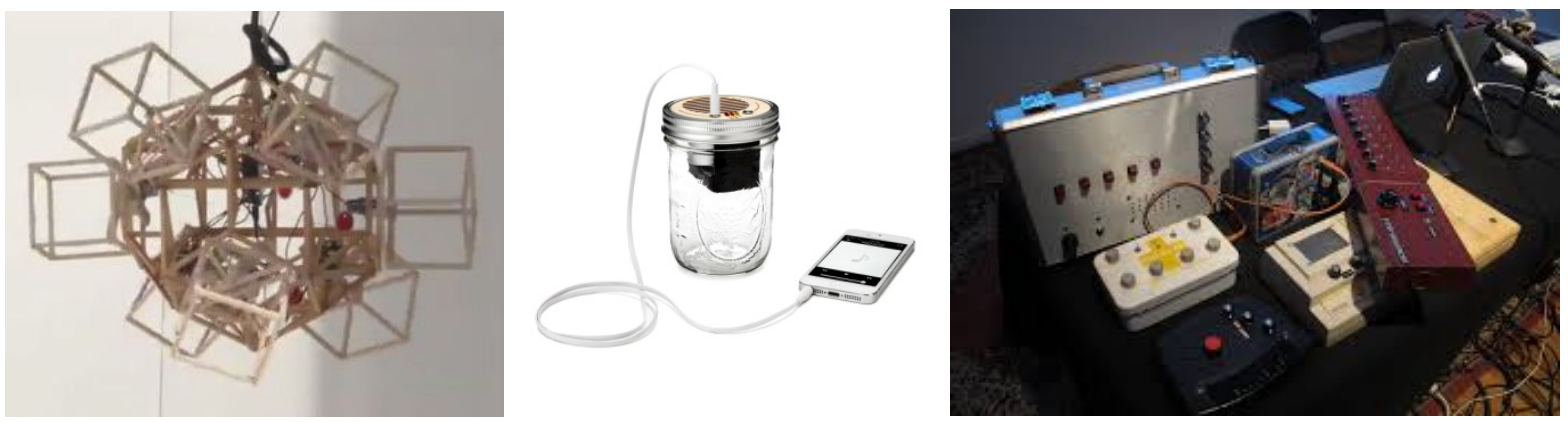

Figure 3. Musical Artifacts of the Makers

Alejandro's pathway seems somewhat standard for engineering; he had six years of engineering schooling, which allowed him to obtain a Mechanical Engineering degree with a major in Mechatronics. He attributes his theory-heavy formal engineering education experiences to enabling him to "look for things and figure out things". However, he wished his formal engineering education had more lab experiences and contests because "it's also frustration that teaches you a lot". Like many engaged engineering students, he sought out informal engineering education experiences by participating in an engineering society; specifically for Alejandro, he would build and present Rube Goldberg devices at science fairs. Alejandro became familiar with the label "Maker" when he was invited to present his robots at the Maker Faire. His drive for making came from the ability to go "against the socially accepted project in engineering school". He pursued the intersection between art and engineering through his making, allowing dance and music to inspire the creation of his robots. When his peers in engineering school tried to label him as an artist for making non-traditional engineering devices, he would respond to them saying, "I'm not an artist. I'm just an engineer that creates moving things." When asked what his future aspirations are, Alejandro reminds us that his artifact at the Maker Faire was the first performance for his dancing robots and that he has four more performances to make to represent different forms of dance (e.g., Bolero). While working a technical day job, he has launched a robotics start-up to pursue his interests in dancing, musical robots. Alejandro's pathway reflects one of a traditional engineer inspired and informed by his art.

Cane's pathway is another example of one that seems standard for engineering; he has an engineering degree in manufacturing engineering and is working as a consultant using the knowledge he gained from his engineering education while also running a business that relies upon manufacturing and electrical engineering knowledge and skills to make musical artifacts (e.g., modeling, casting, using Solid Works). Like Alejandro, Cane participated in informal engineering education experiences; however, Cane's focus was on his interest in teaching, so he sought out experiences in this vein (e.g., being a mentor for FIRST Robotics). His passion for the 
arts also led him to experiences outside of engineering (e.g., teaching ceramics and woodworking). A defining life event for Cane was growing up with a dad who was an electrical engineer and working on projects with him while learning technical and non-technical skills (e.g., soldering and wood working). He also attributed engineering projects in the science classroom as shaping his pursuit of an engineering degree. Cane's identity as an "inventor" drove him to manufacturing engineering whereby he learned "how to make things". Once again, his passion for the arts led him to launch a business where he could combine his engineering knowledge and skills with music. Unlike Alejandro, he did not see a disconnect with engineering and the work that he is doing; rather, he wishes that his formal engineering education could have been extended to include developing interpersonal skills and business skills to enable people to leverage their ideas and pursue their goals. According to Cane, his future will include continuing to make the things he is making, to expand his business to other products, and to get involved with teaching again. Cane's pathway reflects one that was driven by early childhood experiences and a pursuit to use his engineering education to implement his art.

Stephen's pathway is dissimilar from Cane and Alejandro in that he is trained as an artist and works as a professor of art at a school of art design. Stephen points to positive experiences with art from an early age and how art "engaged" him. To Stephen, interacting with the world around him and learning new skills and knowledge is critical. He pursued the arts because "it's an excuse to learn everything". His knowledge and skills span a wide array (e.g., wood working, modeling, casting, materials, and drawing). Through his formal education in sculpture and ceramics, he became interested in technology. "I've always been interested in technology and oddly I got into sound as an art form from sculpture". Through this interest, he began to learn about electronics and made "boxes that make noise". He became involved with informal education activities that support technical activities, including a group dedicated to doing things with electronics. From his musical artifacts, he formed a group that mimics that of jazz improvisation, where the members "have a relationship with each other even before they get on stage and have a relationship with the instruments". When asked how he learned to make his musical artifacts, he points to his formal art education and self-directed learning. He points out that he is interested in engineering and that he would have pursued had it been available to him.

\section{If I had had somebody actually advising me when I was getting out of high school and going to college and I knew engineering as a career, I might have been an engineer to be honest, because I love engineering as a concept of being aware of your world and being in your world.}

To Cane, engineering is "taking that knowledge of the world and creating because it is a very creative endeavor, creating something new that exists in that world that changes how people interface with that world." Recognizing the similarity with art, he says, "that's what art is all about at a certain level." His future aspirations are to keep making, specifically electronics, and to continue being an "academic artist" that enables him to pursue making with technology. Although his pathway differs from that of an engineering pathway, he has overlap in the knowledge and skills he has obtained and his purpose for making. His pathway is one that is exemplary of many others at Maker Faire: those who did not pursue engineering, but that had intrinsic interest and value for making and technical activities. 


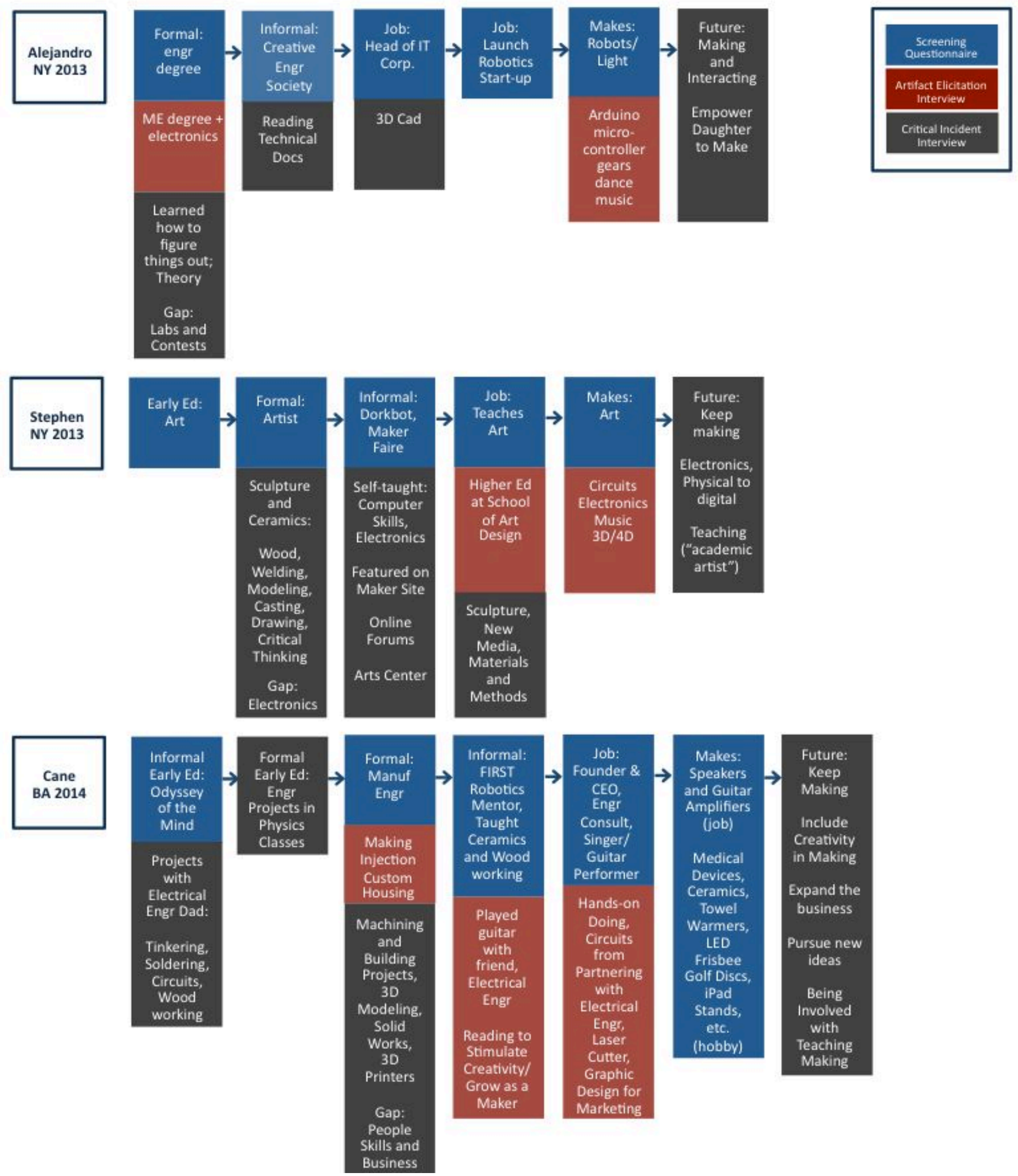

Figure 4. Parallel Pathways for the Makers of Musical Artifacts

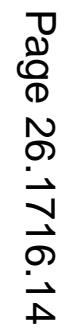




\section{Discussion}

\section{RQ1. Learning from Adult Makers to Inform Pathways to Engineering}

Adult makers show us that engineering is often not a binary category where one is either an engineer or a non-engineer. Instead we see a wide range of actors with widely varying skill sets engaged in engineering activities. More importantly, we see non-engineers valuing engineering expertise and knowledge in new ways through the lens of making. Likewise engineers are either discovering new outlets for their existing engineering skills or learning new engineering and non-engineering skills in pursuit of their passions. While this work is still preliminary, it may showcase some ways in which engineering education can be enhanced to better reach the goals outlined in The Engineer of 2020. If adults are finding interdisciplinary projects framed by personal passion as a way of learning practical ingenuity, creativity, and some analytic skills, perhaps there is a way educators can harness student passions in a similar manner to achieve similar results. Furthermore, the interest shown by non-engineers for learning engineering as adults, along with existing engineers expanding their scope of knowledge could have ramifications in the adult education sector. Perhaps there is a currently unmet demand for adult education in engineering, which could be met by existing universities offering, for example, night courses on circuits for non-engineers. Finally, as shown by the quote presented above, "If I had had somebody actually advising me when I was getting out of high school and going to college and I knew engineering as a career, I might have been an engineer to be honest, because I love engineering as a concept of being aware of your world and being in your world.", engineering is perhaps being presented to young adults in a way that obfuscates the creativity and impact that engineering can have on the world around them. When adult artists suggest they would have chosen different career paths if they had been presented with engineering as a creative career which embraces practical ingenuity, ethics, and communication as well analytic skills, then there is perhaps a better way going forward to market engineering to incoming students.

Through an in-depth exploration with qualitative inquiry, a new perspective is offered that can inform us of how access to engineering from qualified learners may be improved. Makers are self-directed learners and have diverse technical and non-technical backgrounds; many may be qualified to enter engineering majors. The study of maker unveils opportunities and new dimensions for access and migration to engineering.

\section{RQ2. Contributions of the Methods to Studying Pathways}

Combining the three data collection sets (screening questionnaire, artifact elicitation interview, and critical incident interview) provide a rich narrative of each Maker's pathway. With each stage of data collection, there was something to be learned about the Makers' pathways. This was useful in understanding the breadth of Makers' pathways and how they overlap with one another and intersect with engineering.

The screening questionnaire was useful in unearthing the major milestones along the individual's pathway (e.g., degrees, clubs, and what they make). However, the responses from the screening questionnaire provided no context for making. With this data set alone, individual pathways 
might have looked linear (e.g., an engineering major working in a technical field) and overlooked other important events and turning points in the pathways.

The artifact elicitation interview provided a context for the Makers' pathways. By providing an opportunity to conduct a live-action interview (i.e., interviewing the Maker with their artifact), we were able to ask probing questions about the artifact and the knowledge, skills, and attitudes that the Maker learned from making. By watching the Maker operate and showcase their artifact, we gained an understanding of the functionality of the device and technical and non-technical components, which informed probing interview questions. From the probing interview questions, Makers had the opportunity to bring up experiences they have had in their pathways (e.g., examples of learning knowledge and skills through self-directed learning and informal education activities). The setting for artifact elicitation interviews was exciting. The Maker Faires were filled with people that had enthusiasm for the artifacts. Makers were ready to show their artifact and interact with the public. These interviews could only last fifteen minutes in order to be respectful of the participants' time and allow them to interact with other attendees.

The critical incident interview further extended our understanding of the Makers' pathways by providing an opportunity to ask the Makers to walk us through their critical points in their life (e.g., education, career, and future aspirations). By conducting this interview via Skype, the Makers were able to give more of their time to responding to questions and were able to elaborate upon their pathways to making.

From these methods, we only get a snapshot, though a very detailed snapshot, of one of artifact at one point in time. The critical incident interview is in relation to this one artifact and does not provide a fully fleshed out life history. However, when aggregated, these snapshots form a broader picture that describes the community of Makers in a useful way and allows us to see possibilities for broadening engineering pathways.

\section{Concluding Thoughts and Future Work}

A more inclusive vision of engineering crossed with making could build future engineering capacity as well as raise awareness to the general public of the work and impact such work offers. The pathways presented in this study are far different than what many early engineers imagine. Instead of a linear progression of high school to college to work to professional engineer qualification to retiring someday, these pathways show that engineers can be much more broadly interdisciplinary and engage with multiple fields, both within engineering and with disciplines such as art or business. Engineering is often perceived as an activity lacking in creativity and, for some, meaning. However, interdisciplinary interactions with engineering can show adults, and presumably youths, that engineering is a creative way to interact with and affect the world around you and could be a way to improve access to engineering. These pathways show that engineering may be approachable for non-engineers involved in making and technical activities. The examples of maker pathways could be used as example stories for how students may pursue engineering in the future.

Identifying appropriate methods for studying pathways remains a challenge. There are many dimensions to examine with an individual's life path. In the case of Makers, these pathways are 
nuanced, non-linear, and include pivots due to defining life events (e.g., engineer to entrepreneur). The qualitative research approach of constructivist grounded theory, using artifact elicitation interview and critical incident interview methods, is a useful contribution to telling the story of the life path and providing a deeper look at the knowledge and skills that are learned that may be related or useful to engineering. Opportunities exist to examine how to visualize these complex pathways. Additionally, opportunities may exist to export the interview techniques for other uses. Perhaps entrepreneurs developing products could be interviewed to better understand the values and skills behind product development or robotics engineers could be interviewed to gain insight into how they understand the creation of a robot. Combined with critical incident interviews this sort of analysis offers new insights that relate to new opportunities for pathways to engineering. The life pathways of makers can begin to change the conversation to highlight the efficacy and possibilities for those who are engaged in making and seeking meaning and impact through their studies. The stories and life pathways of adult learners engaged in Making can offer valuable insight into how we might identify practices that promote the access and success of a larger and more diverse population of students.

\section{Acknowledgements}

This material is based upon work supported by the National Science Foundation under Grant No. 1232772 .

\section{References}

1. Atman, C. J., Sheppard, S. D., Turns, J., Adams, R. S., Fleming, L. N., Stevens, R., Streveler, R. A., Smith, K. A., Miller, R. L., Leifer, L. J., Yasuhara, K., \& Lund, D. (2010). Enabling engineering student success: The final report for the Center for the Advancement of Engineering Education. San Rafael, CA: Morgan \& Claypool Publishers.

2. Bushey-Mc-Neil, J., Ohland, M., \& Long, R. (2014). Nontraditional student access and success in engineering. Proceedings of the American Society for Engineering Education (ASEE) Annual Conference \& Exposition, Indianapolis, IN.

3. Ohland, M., Sheppard, S., Lichtenstein, G., Eris, O., Chachra, D. \& Layton, R. (2008). Persistence, engagement, and migration in engineering programs. Journal of Engineering Education. 97(3): 259-278.

4. S Jordan \& M Lande (2013). Work in Progress: Should Makers Be the Engineers of the Future? Frontiers in Education Conference. Oklahoma City, OK. October 23-26.

5. Jordan, S. \& Lande, M. (2014). Methods for Examining the Educational Pathways of Adult Makers. American Society for Engineering Education Conference. Indianapolis, IN. June 15 - 18.

6. Oplinger, J., Heiman, A., Dickens, M., Foster, C., Jordan, S. \& Lande, M. (2014). Making and Engineering: Understanding Similarities and Differences. American Society for Engineering Education Conference. Indianapolis, IN. June $15-18$.

7. Brand, S. (1971). The last whole earth catalog: Access to tools. New York: Random House.

8. McFedries, P. (2007, June) The hobbyist renaissance. IEEE Spectrum. 
9. Heile, A. (2006). Survival research labs. Ambidextrous Journal of Design: Endless Summer 2006, 26-29. Retrieved February 10, 2012 from http://ambidextrousmag.org/issues/04/pdf/i4p27-29.pdf.

10. Yen, C. (2008). Lee Krasnow: A puzzling designer. Ambidextrous Journal of Design: Secret Winter 2008, 15-17. Retrieved February 10, 2012, from http://ambidextrousmag.org/issues/08/article.php?i8p15_17.

11. Foster, C., Lande, M. \& Jordan, S. (2014). An Ethos of Sharing in the Maker Community. American Society for Engineering Education Conference. Indianapolis, IN. June 15 - 18.

12. Tech Shop (n.d.). Retrieved February 10, 2012, from http://techshop.ws.

13. More than just digital quilting. (2011, December 3). The Economist. Retrieved April 7, 2013, from www.economist.com/node/21540392.

14. MAKE Magazine. (n.d.). Retrieved December 28, 2013, from http://www.makezine.com

15. Honey, M., \& Siegel, E. (2010). Proceedings from the Innovation, Education \& Maker Movement Workshop. New York Hall of Science.

16. Tweney, D. (2009, March 29). DIY freaks flock to 'hacker spaces' worldwide. Wired. Retrieved April 13, 2013 from http://www.wired.com/gadgetlab/2009/03/hackerspaces.

17. Crotty, M. (1998). The foundations of social science research: Meaning and perspective in the research process. Thousand Oaks, CA: Sage Publications.

18. Papert, S. (1991). Situating constructionism. In I. Harel \& S. Papert (Eds.) Constructionism. Norwood, NJ: Ablex Publishing.

19. Charmaz, K. (2006). Constructing grounded theory. Thousand Oaks, CA: Sage Publications.

20. Strauss, A., \& Corbin, J. (1998). Basics of qualitative research: Techniques and procedures for developing grounded theory (2nd ed.). Thousand Oaks, CA: Sage.

21. Harper, D. (2002). Talking about pictures: A case for photo elicitation. Visual Studies, 17(1), 1326.

22. Flanagan, J. (1954). The critical incident technique. Psychological Bulletin, 51, 327-58.

23. Krathwohl, D. R. (2002). A revision of Bloom's taxonomy: An overview. Theory into Practice, 41(4), 212-218.

24. Martin, L., \& Gourley-Delaney, P. (2010). A photograph-based measure of students' beliefs about math. In K. Gomez, L. Lyons, \& J. Radinsky (Eds.), Proceedings of the 9th international Conference of the Learning Sciences - Volume 2 (Chicago, Illinois, June 29 - July 02, 2010). International Society of the Learning Sciences, 482-483.

25. Patton, M. Q. (2002). Qualitative research \& evaluation methods (3rd ed.). Thousand Oaks, CA: Sage Publications.

26. Geertz, C. (1973). The interpretation of cultures: Selected essays. New York: Basic Books.

27. Klein, G. A., Calderwood, R., \& Macgregor, D. (1989, May/June). Critical decision method for eliciting knowledge. IEEE Transactions on Systems, Man, and Cybernetics, 19(3).

28. Klein, G. (1998). Sources of power: How people make decisions. Cambridge, MA: MIT Press.

29. Glaser, B. G. (1978). Theoretical sensitivity: Advances in the methodology of grounded theory. Mill Valley, CA: Sociology Press.

30. Boyatzis, R. E. (1998). Transforming qualitative information: Thematic analysis and code development. Thousand Oaks, CA: Sage.

31. VanWynsberghe, R. \& Khan, S. (2008). Cultivating the under-mined: Cross-case analysis as knowledge mobilization. Qualitative Social Research, 9(1): 34. 